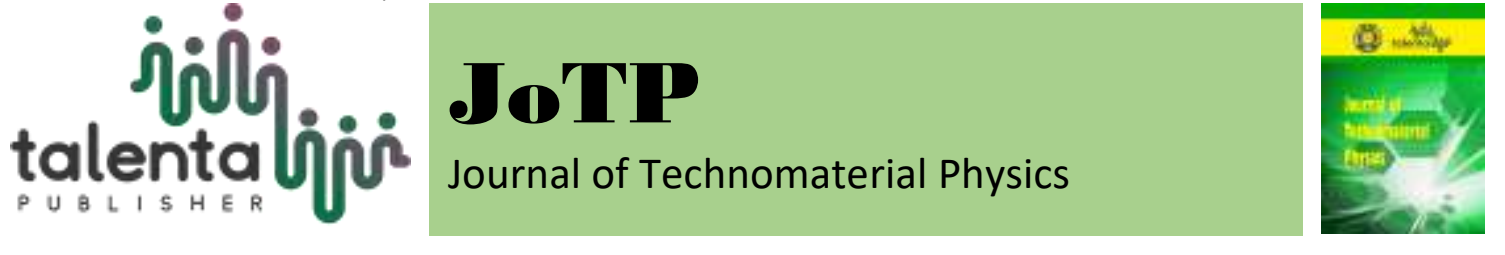

\title{
Analysis of Curvature in Fiber Optic Cable for Macrobending-Based Slope Sensor
}

\author{
Imam Mulyanto ${ }^{1}$, Syahrul Humaidi ${ }^{2}$, and Roy Efendy Sihotang ${ }^{3}$ \\ ${ }^{1}$ Physics Research Center - Lembaga Ilmu Pengetahuan Indonesia (LIPI) Kawasan PUSPIPTEK, \\ Tangerang Selatan 1531, Indonesia \\ 2,3 Department of Physics, Faculty of Mathematics and Natural Science, Universitas Sumatera Utara \\ 20155, Indonesia
}

\begin{abstract}
The analysis of fiber optics for macro bending-based slope sensors using SMF28 single-mode optical fibers has been successfully conducted. Fiber optics were treated to silicon rubber molding and connected with laser light and power meters to measure the intensity of laser power generated. The working principle was carried out using the macrobending phenomenon on single-mode optical fibers. The intensity of laser light in fiber optic cables decreases in the event of indentation or bending of the fiber optic cable. Power losses resulting from the macrobending process can be seen in the result of the information sensitivity of fiber optics to the change of angle given. From the results of the study, the resulting fiber optic sensitivity value is $-0.1534^{\circ} / \mathrm{dBm}$. The larger the angle given, the lower the laser intensity received by the power meter.
\end{abstract}

Keyword: Fiber Optics, Tilt Sensor, Laser, Macro Bending

Received 5 February 2021 | Revised [19 February 2021] | Accepted [25 February 2021]

\section{Introduction}

Fiber optic technology has developed its use in the field of telecommunications, computers, industry, medical equipment, as well as in the field of military applications and daily life. This technology is a communication network system that in the delivery and receiving of information signals in the form of light beams, using optical sources, with fiber optics as the transmission media [1-4]. These thin strands are arranged in bundles called fiber optic cables. Fiber optic cable serves to transmit (send) light without loss. In another sense, the light that is successfully sent from one place to another experiences only a very small number of signal loss [5]. Optical fibers are pure optical strands that are very thin (as thin as human hair) and can carry digital information data for long distances. These thin strands are arranged in bundles called fiber optic cables and serve to transmit light, almost without loss. That is, the light that is successfully sent from one place to another has only lost a very small amount of signal. The working principle of fiber optic cable uses the principle of perfect reflection (total internal reflection) by utilizing the

\footnotetext{
*Corresponding author at: Jl. Bioteknologi No.1 Kampus USU, Medan, Indonesia, 20155

E-mail address: imam004@lipi.go.id
} 
difference in refractive index between the core layer or its cladding [6]. The advantages of fiber optics as sensors are that they cannot interact directly with measuring objects, then do not use electricity as a cue, high measurement accuracy, and small sizes [7-9].

Fiber optic is an implementation of the concept of light propagation properties in optical medium. The light inside the fiber optics is difficult to get out because the bias index of the glass is greater than the refractive index of the air. The light sources that can be used are LASER and LED. Lasers and LEDs have a very narrow spectrum. Fiber optics are not only developed in the field of communication but also used in the needs of various sensors. The advantages of fiber optic sensors compared to other sensors are more precise, undisturbed EMI, low noise, low needed power supply, and power supply can be placed away from the location. Fiber optic technology can be applied in various fields, both in the field of telecommunications, medicine, industry and the general public. In the field of telecommunications, fiber optics are used as trunk, backbone, route junction, sea cable, and customer loop, inter-computer channels (LAN), and cable TV channels. Fiber optics can also be used as a sensor for measurement of pressure, there is or is not an object and temperature) [10].

One of the slope angle sensors used is MEMS (Micro Electro Mechanical system) sensor. MEMS sensors can be used to measure acceleration, position, or surprise. The development of mems accelerometer on the inclinometer is based on slope readings obtained from the static conditions of measurable gravitational acceleration. The inclinometer can be used by embedding it in the ground through a flowing pipe for the inclinometer line. In the event of movement in the soil layer, the pipe containing the inclinometer will undergo bending. The inclinometer will measure the angle of inclination of the pipe against the normal angle of ground level so that the information will be able to how large the ground shift is occurring at a certain depth point. But the use of this application is portable, and must be done periodically and continuously by visiting certain observation points directly [11-13].

MEMS accelerometer can be used for sensors on inclinometers observing ground motion. This sensor has slope reading capability on each axis indicated from the output voltage. Slope readings on each axis have no effect on different axes. MEMS Accelerometer is undoubtedly an inclinometer sensor [14]. The design, realization and characterization of slope sensors in the form of Piezoelectric Sensor-based Micro Electro Mechanical System (MEMS) has been developed by Lijun Tang, et. al. (2009), this system has been characterized and able to obtain sensitivity of $0.025 \mathrm{mV} /{ }^{\circ} 2$ [15]. The theoretical characterization of the system is able to produce a standard deviation of 0.43874 .

Fiber optic inclinometer is a measuring instrument used to measure the slope of a field. This tool can be used as a slope sensor of a field in the ground that can be seen from the change of angle. There are two types of bending that cause losses in fiber, namely micro-bending (microbending) and macrobending. Both arise for different reasons, and cause losses with two 
different mechanisms. Arch is one of the causes of laser transmission losses in fiber optics. At the time of the arch with a certain diameter, not all lasers will be guided by fiber optics but there are some that come out as a result of the coming angle changes that have exceeded the critical angle. When the fiber optic arch is made with a shrinking diameter, the angle comes to be smaller so that many lasers come out and cause a weaker laser intensity received.

The main factor of the advantages of using optical fibers is its immunity to electromagnetic interference (light signals that radiate in optical fibers are not affected by electromagnetic fields). The light inside the fiber optics is difficult to get out because the bias index of the glass is greater than the bias index of the air, besides it can be used in humid or wet environments and can be used in the ground. But the shortcomings of the use of fiber optics are the narrow angle range, exponential curves, and weak fiber optic construction so that in its use required a layer of amplifier as protection [16-20]. Based on the background, research will be made on Curving Analysis on Fiber Optic Cable as Macro Bending Based Slope Sensor". As for this research, the optical source used is a laser with a wavelength of $1,310 \mathrm{~nm}$.

\section{Methods}

\subsection{Functional Design}

This research tested fiber optics to be used as a tilt sensor based on macro bending using singlemode optical fiber SMF-28. Fiber optics are treated to silicon rubber moulding first, then connected with laser light and power meters to see the intensity of laser power generated.

\subsection{Structural Design}

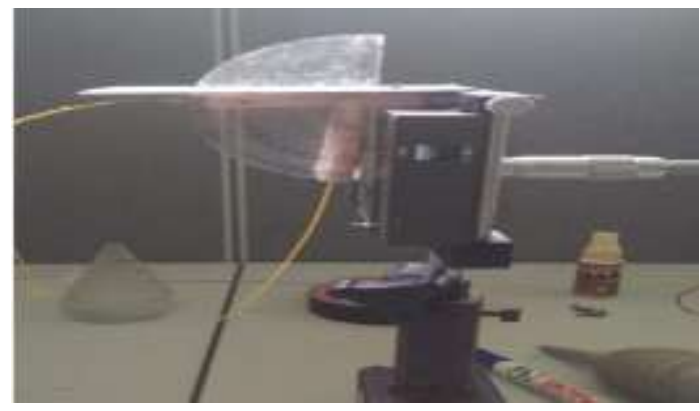

Figure 1. Set up Experiment 
An optical fiber in a silicone rubber field of a certain length is curved by rotating the screw micrometer constantly as shown in Figure 1. When pressured in the field of the screw micrometer, the optical fiber will curve or bend simultaneously with the pressured field, resulting in loss of transmission. The data was taken from changes in the angle of inclination of the fiber optics in the field and the intensity of the laser transmitted on the fiber optics by measuring them using a digital power meter and multimeter. The flowchart of this research is shown in Figure 2.

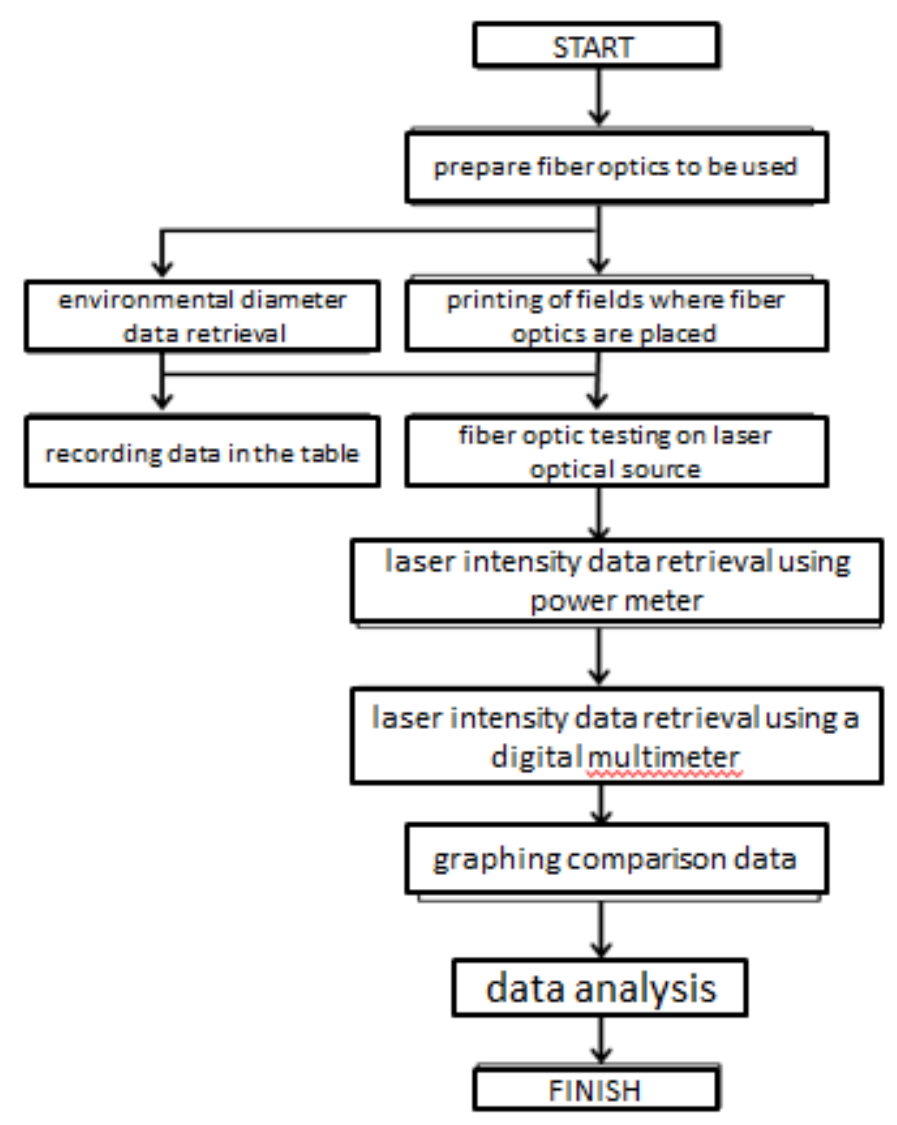

Figure 2. Flowchart of the experiment

\section{Result and Discussion}

\subsection{Curvature Diameter Measurement}

Fiber optics used in this research is fiber optic type single mode with type or brand SMF-28 (TM) Fiber. Variations in fiber optic curvature diameter used in this study were measured using Acrylic. The measurement results in acrylic diameter obtained results of $55 \mathrm{~mm}, 50 \mathrm{~mm}, 45$ mm, $40 \mathrm{~mm}, 35 \mathrm{~mm}, 30 \mathrm{~mm}, 25 \mathrm{~mm}, 20 \mathrm{~mm}, 15 \mathrm{~mm}$.

\subsection{Measurement of Curved Diameter Laser Intensity Using Power Meter}

Table 1 is the result of taking laser intensity data on power meters through the diameter of optical fiber curvature in acrylic. After the data retrieval process, a graph is made that contains 
the intensity of the laser on the power meter and the diameter of the fiber optic curvature that has been determined. The input power in the laser through fiber optics is $3 \mathrm{~mW}$.

Table 1. Results of SMF-28(TM) Fiber Curvature Laser Intensity Measurement

\begin{tabular}{ccc}
\hline No. & Diameter $(\mathrm{mm})$ & Laser Intensity $(\mu \mathrm{W})$ \\
\hline 1 & Straight & 590.2 \\
2 & 55 & 589.8 \\
3 & 50 & 589.5 \\
4 & 45 & 588.7 \\
5 & 40 & 588.2 \\
6 & 35 & 587.9 \\
7 & 30 & 587.1 \\
8 & 25 & 584.3 \\
9 & 20 & 562.0 \\
10 & 15 & 455.4 \\
\hline
\end{tabular}

Figure 3 shows the laser intensity measurement of SMF-28(TM) Fiber Curvature Diameter. The decrease in laser intensity value resulting from changes in fiber optic arch diameter that is getting smaller occurs at a diameter of $15 \mathrm{~mm}$. This indicates that sensitivity occurs at a diameter of $15 \mathrm{~mm}$.

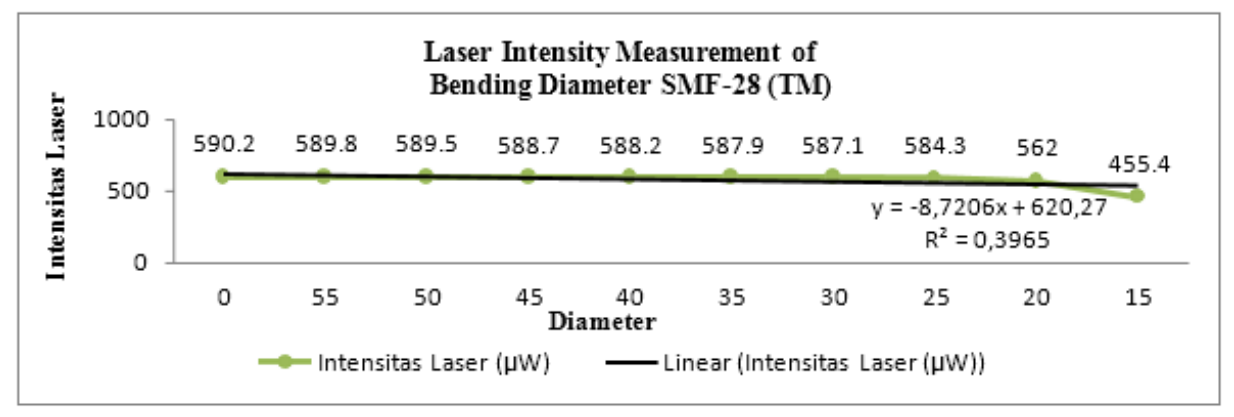

Figure 3. Laser Intensity Measurement Graph Smf-28 Curvature Diameter (TM) Fiber

\subsection{Laser Intensity Measurement Against Angle Change Using Power Meter}

The tables show the result of taking laser intensity data on power meters through angular changes in fiber optics. The creation of a graph that contains the intensity of the laser on the power meter and changes in the angle of fiber optics that have been determined is done after the process of retrieving data as many as 3 repetitions (Table 2, Table 3, Table 4, Figure 1, Figure 4, Figure 5, and Figure 6). In measurements 1 to 3, laser intensity values are not much different when angular changes occur in SMF-28 (TM) Fiber optic fibers. 
Table 2. Measurement Results Laser Intensity I SMF-28(TM) Fiber

\begin{tabular}{ccc}
\hline No. & Angle Change $\left({ }^{\circ}\right)$ & Laser Intensity $(\mu \mathrm{W})$ \\
\hline 1 & 0 & 437.8 \\
2 & 1 & 422.3 \\
3 & 2 & 412.3 \\
4 & 3 & 406.0 \\
5 & 4 & 354.6 \\
6 & 5 & 341.3 \\
7 & 6 & 314.2 \\
8 & 7 & 314.0 \\
9 & 8 & 295.2 \\
10 & 9 & 288.3 \\
11 & 10 & 292.5 \\
12 & 11 & 290.9 \\
13 & 12 & 278.8 \\
14 & 13 & 257.7 \\
15 & 14 & 260.3 \\
16 & 15 & 259.0 \\
\hline
\end{tabular}

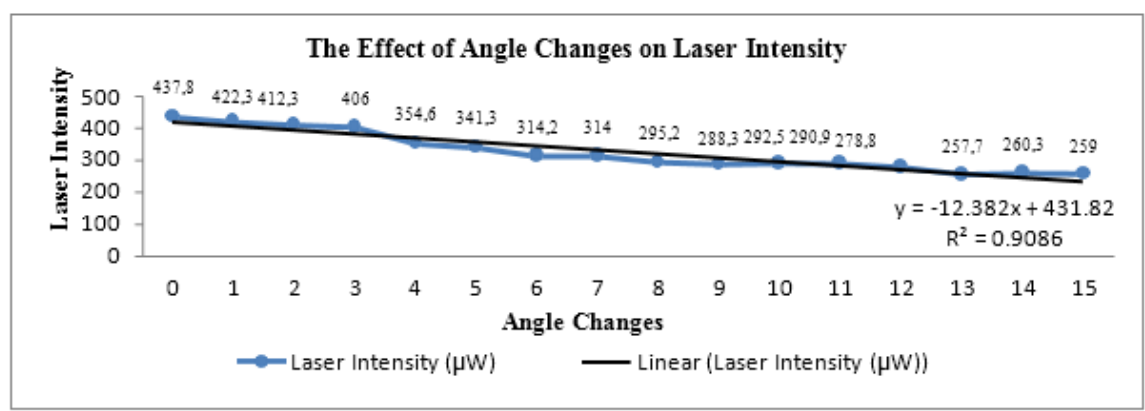

Figure 4. Graph of The Effect of Angle Changes on Laser Intensity I

Table 3. Measurement Results Laser Intensity II SMF-28(TM) Fiber

\begin{tabular}{ccc}
\hline No. & Angle Change $\left({ }^{\circ}\right)$ & Laser Intensity $(\mu \mathrm{W})$ \\
\hline 1 & 0 & 436.4 \\
2 & 1 & 418.7 \\
3 & 2 & 410.6 \\
4 & 3 & 408.5 \\
5 & 4 & 399.8 \\
6 & 5 & 399.6 \\
7 & 6 & 356.4 \\
8 & 7 & 342.0 \\
9 & 8 & 319.9 \\
10 & 9 & 317.6 \\
11 & 10 & 303.5 \\
12 & 11 & 288.9 \\
13 & 12 & 288.0 \\
14 & 13 & 286.3 \\
15 & 14 & 289.4 \\
16 & 15 & 272.4 \\
\hline
\end{tabular}




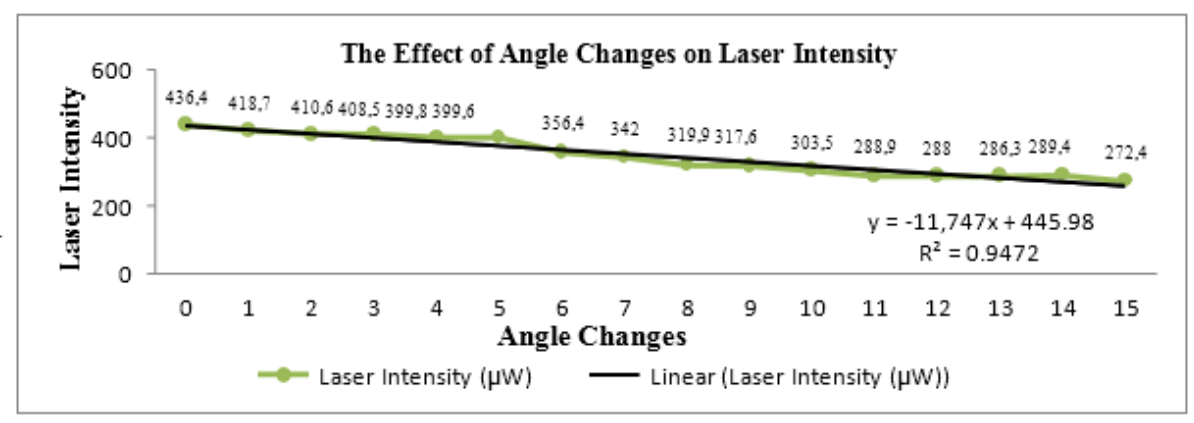

Figure 5. Graph of The Effect of Angle Changes on Laser Intensity II

Table 4. Measurement Results Laser Intensity III SMF-28(TM) Fiber

\begin{tabular}{ccc}
\hline No. & Angle Change $\left(^{\circ}\right)$ & Laser Intensity $(\mu \mathrm{W})$ \\
\hline 1 & 0 & 429.2 \\
2 & 1 & 418.3 \\
3 & 2 & 403.5 \\
4 & 3 & 402.2 \\
5 & 4 & 395.8 \\
6 & 5 & 351.6 \\
7 & 6 & 324.6 \\
8 & 7 & 340.7 \\
9 & 8 & 317.9 \\
10 & 9 & 302.8 \\
11 & 10 & 282.9 \\
12 & 11 & 285.9 \\
13 & 12 & 285.8 \\
14 & 13 & 287.9 \\
15 & 14 & 267.5 \\
16 & 15 & 255.6 \\
\hline
\end{tabular}

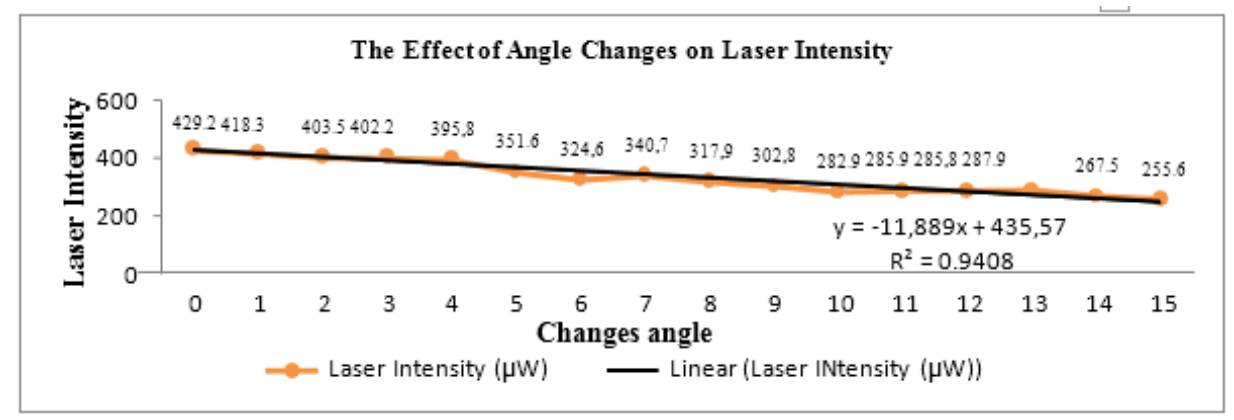

Figure 6. Graph of The Effect of Angle Changes on Laser Intensity III 
Table 5. Results of Laser Intensity Power Conversion $(\mu \mathrm{W})$ to $\mathrm{dBm}$

\begin{tabular}{|c|c|c|c|c|c|}
\hline \multirow{2}{*}{ No. } & \multirow{2}{*}{$\begin{array}{c}\text { Angle } \\
\text { Changes }\left({ }^{\circ}\right)\end{array}$} & \multicolumn{3}{|c|}{ Power Conversion $(\mathrm{dBm})$} & \multirow{2}{*}{ Mean } \\
\hline & & Measurement I & Measurement II & Measurement III & \\
\hline 1 & 0 & -3.59 & -3.60 & -3.63 & -3.60 \\
\hline 2 & 1 & -3.80 & -3.77 & -3.91 & -3.82 \\
\hline 3 & 2 & -3.88 & -3.87 & -3.88 & -3.87 \\
\hline 4 & 3 & -3.92 & -3.92 & -3.96 & -3.93 \\
\hline 5 & 4 & -4.34 & -3.96 & -4.02 & -4.10 \\
\hline 6 & 5 & -4.62 & -3.95 & -4.52 & -4.36 \\
\hline 7 & 6 & -5.01 & -4.43 & -4.83 & -4.75 \\
\hline 8 & 7 & -5.01 & -4.60 & -4.67 & -4.76 \\
\hline 9 & 8 & -5.27 & -4.90 & -4.96 & -5.04 \\
\hline 10 & 9 & -5.39 & -4.95 & -5.22 & -5.18 \\
\hline 11 & 10 & -5.36 & -5.14 & -5.46 & -5.32 \\
\hline 12 & 11 & -5.36 & -5.39 & -5.45 & -5.40 \\
\hline 13 & 12 & -5.47 & -5.41 & -5.49 & -5.45 \\
\hline 14 & 13 & -5.94 & -5.42 & -5.37 & -5.57 \\
\hline 15 & 14 & -5.97 & -5.41 & -5.65 & -5.67 \\
\hline 16 & 15 & -5.96 & -5.52 & -5.82 & -5.76 \\
\hline
\end{tabular}

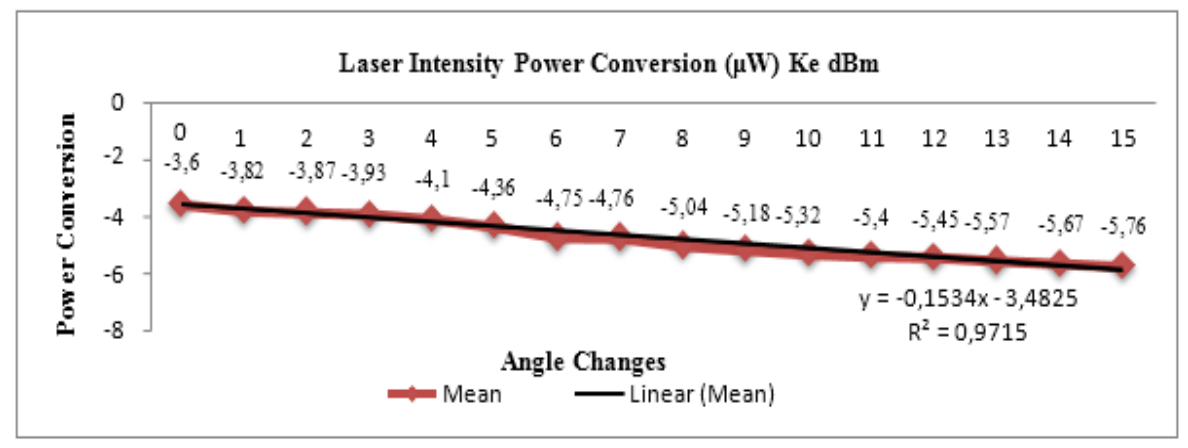

Figure 7. Graph of Laser Intensity Power Conversion $(\mu \mathrm{W})$ To dBm

Then in Table 5 and Figure 7 show the results of laser intensity measurement that has been converted into dBm unit form on SMF-28 (TM) Fiber optical fiber. This measurement is done by repeating 3 times the experiment. In measurements 1 to 3, laser intensity values are not much different when angular changes occur in SMF-28 (TM) Fiber optic fibers. In this power conversion is obtained the results of unstable data that we can see on the graphs that are up and down.

\subsection{Laser Voltage Measurement Against Angle Change Using Digital Multimeter}

The following is the result of taking laser Voltage data on digital multimeter through angle change in optical fiber (Table 6, Table 7, Table 8, Figure 8, Figure 9, nd Figure 10). After the data retrieval process is done 3 repetitions, then the creation of a graph that contains the laser voltage on the digital multimeter and changes the angle of fiber optics that has been determined. 
Table 6. Laser Voltage Results Using Digital Multimeter I

\begin{tabular}{ccc}
\hline No. & Angle Changes $\left({ }^{\circ}\right)$ & Voltage $(\mathrm{V})$ \\
\hline 1 & 0 & 3.06 \\
2 & 1 & 2.94 \\
3 & 2 & 2.89 \\
4 & 3 & 2.88 \\
5 & 4 & 2.83 \\
6 & 5 & 2.86 \\
7 & 6 & 2.34 \\
8 & 7 & 2.22 \\
9 & 8 & 2.16 \\
10 & 9 & 2.07 \\
11 & 10 & 2.04 \\
12 & 11 & 2.09 \\
13 & 12 & 2.08 \\
14 & 13 & 2.03 \\
15 & 14 & 1.97 \\
16 & 15 & 1.86 \\
\hline
\end{tabular}

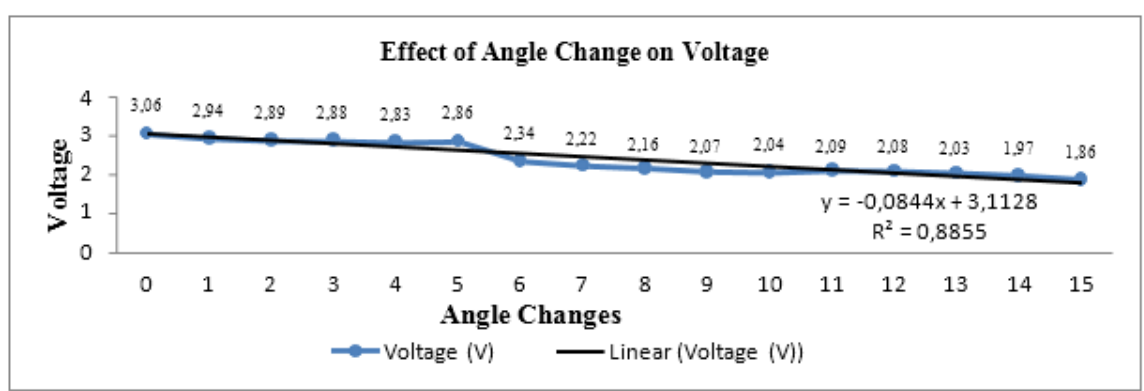

Figure 8. Graph of The Effect of Angle Change on Voltage I

Table 7. Laser Voltage Results Using Digital Multimeter II

\begin{tabular}{ccc}
\hline No. & Angle Changes $\left(^{\circ}\right)$ & Voltage $(\mathrm{V})$ \\
\hline 1 & 0 & 3.13 \\
2 & 1 & 2.95 \\
3 & 2 & 2.90 \\
4 & 3 & 2.86 \\
5 & 4 & 2.84 \\
6 & 5 & 2.82 \\
7 & 6 & 2.84 \\
8 & 7 & 2.74 \\
9 & 8 & 2.60 \\
10 & 9 & 2.37 \\
11 & 10 & 2.39 \\
12 & 11 & 2.45 \\
13 & 12 & 2.36 \\
14 & 13 & 2.28 \\
15 & 14 & 2.24 \\
16 & 15 & 2.15 \\
\hline
\end{tabular}




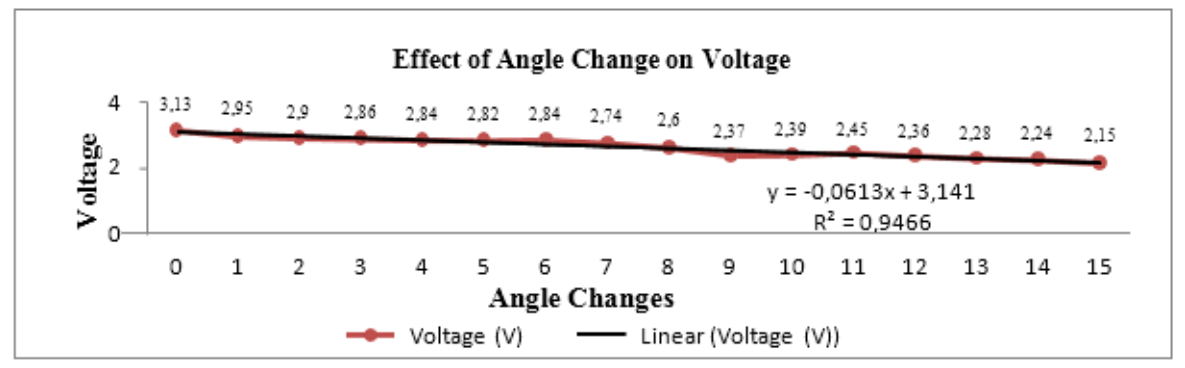

Figure 9. Graph of The Effect of Angle Change on Voltage II

Table 8. Laser Voltage Results Using Digital Multimeter III

\begin{tabular}{ccc}
\hline No. & Angle Changes $\left({ }^{\circ}\right)$ & Voltage $(\mathrm{V})$ \\
\hline 1 & 0 & 3.13 \\
2 & 1 & 3.08 \\
3 & 2 & 2.98 \\
4 & 3 & 2.92 \\
5 & 4 & 2.91 \\
6 & 5 & 2.89 \\
7 & 6 & 2.92 \\
8 & 7 & 2.80 \\
9 & 8 & 2.66 \\
10 & 9 & 2.52 \\
11 & 10 & 2.42 \\
12 & 11 & 2.41 \\
13 & 12 & 2.42 \\
14 & 13 & 2.38 \\
15 & 14 & 2.30 \\
16 & 15 & 2.24 \\
\hline
\end{tabular}

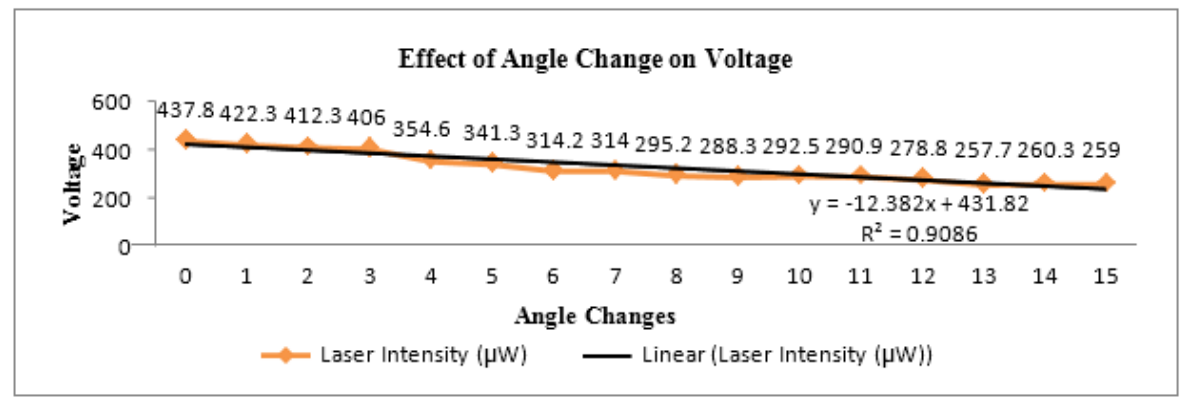

Figure 10. Graph of The Effect of Angle Change on Voltage III

From The first measurement to the third measument obtained a decreased voltage value, so it was concluded that fiber optic patch cord suffered transmission losses (loss) when the angular change occurred. 


\section{Conclusion}

The effect of curvature diameter on optical fiber SMF-28 (TM) Fiber is concluded that the smaller the diameter of the fiber optic, the intensity of the resulting laser will decrease or decrease. A significant decrease in laser intensity occurs at a distance of $15 \mathrm{~mm}$. Then the FIBER OPTIC SMF-28 TM can be used as a tilt sensor, but the resulting value is not accurate or sensitive in angular changes. Measurement results on fiber optic brand SMF-28 TM after treated moulding silicon rubber produced a sensitivity obtained by $-0.1534^{\circ} / \mathrm{dBm}$.

\section{REFERENCES}

[1] R. Tricker, Optoelectronics and fiber optic technology, Newnes, 2002.

[2] C. Massaroni, P. Saccomandi, and E. Schena, "Medical smart textiles based on fiber optic technology: an overview", Journal of functional biomaterials, vol. 6, no. 2, pp.204-221, 2015.

[3] J. V. V. Koelman, J. L. Lopez, and H. Potters, "Fiber optic technology for reservoir surveillance", In International petroleum technology conference, 2011, November.

[4] D. B. Duraibabu, G. Leen, D. Toal, T. Newe, E. Lewis, and G. Dooly, "Underwater depth and temperature sensing based on fiber optic technology for marine and fresh water applications", Sensors, vol. 17, no. 6, p.1228, 2017.

[5] R. Hoss and L. Ptaschek, Manufacturing Methods and Technology Program for Ruggedized Tactical Fiber Optic Cable, ITT ELECTRO-OPTICAL PRODUCTS DIV ROANOKE VA, 1979.

[6] E. Udd, "Fiber optic sensors based on the Sagnac interferometer and passive ring resonator", Fiber optic sensors: An introduction for engineers and scientists, 1991.

[7] D. A. Krohn, T. MacDougall, and A. Mendez, Fiber optic sensors: fundamentals and applications, Bellingham, WA: Spie Press, 2014.

[8] S. Ghetia, R. Gajjar, and P. Trivedi, "Classification of fiber optical sensors", Int. J. Electron. Commun. Comput. Technol, vol. 3, pp.442-445, 2013.

[9] B. Lee, "Review of the present status of optical fiber sensors", Optical fiber technology, vol. 9, no. 2, pp.57-79, 2003.

[10] B. Culshaw, "Optical fiber sensor technologies: opportunities and-perhaps-pitfalls", Journal of lightwave technology, vol. 22, no. 1, pp.39, 2004.

[11] H. Du and R. Bogue, "MEMS sensors: past, present and future", Sensor Review, 2007.

[12] R. Bogue, "Recent developments in MEMS sensors: A review of applications, markets and technologies", Sensor Review, 2013.

[13] S. Beeby, G. Ensel, N. M. White, and M. Kraft, MEMS mechanical sensors, Artech House, 2004.

[14] D. Hanto, B. Widiyatmoko, "Perancangan Sensor dan Antarmuka Inklinometer Waktu Nyata", Prosiding Pertemuan Ilmiah XXVI HFI Jateng \& DIY, Purworejo, Tangerang Selatan: Pusat Penelitian Fisika- LIPI, pp.114-117, 2012.

[15] L. Tang, K. Zhang, S. Chen, G. Zhang, and G. Liu, "MEMS inclinometer based on a novel piezoresistor structure", Microelectronics Journal, vol. 40, no. 1, pp.78-82, 2009.

[16] G. Keiser, Optical fiber communications, Wiley encyclopedia of telecommunications, 2003.

[17] N. Sabri, S. A. Aljunid, M. S. Salim, R. B. Ahmad, and R. Kamaruddin, "Toward optical sensors: Review and applications", In Journal of Physics: Conference Series, vol. 423, no. 1, pp. 012064, 2013, April.

[18] K. A. Fidanboylu and H. S. Efendioglu, "Fiber optic sensors and their applications", In 5th International Advanced Technologies Symposium (IATS'09), vol. 6, pp. 2-3, 2009, May. 
[19] J. Nedoma, M. Fajkus, and R. Martinek, "Measurement of electric current using optical fibers: A Review", Przeglad Elektrotechniczny, vol. 93, no. 11, pp.140-145, 2017.

[20] J. R. Casas and P. J. Cruz, "Fiber optic sensors for bridge monitoring", Journal of bridge engineering, vol. 8, no. 6, pp.362-373, 2003. 